\title{
The interaction of objective and subjective organizations in a localization search task
}

\author{
MARISA CARRASCO and IRENE CHANG \\ Wesleyan University, Middletown, Connecticut
}

\begin{abstract}
We investigated how both objective and subjective organizations affect perceptual organization and how this perceptual organization, in turn, influences observers' performance in a localization search task. Two groups of observers viewing exactly the same stimuli (objective organization) performed in significantly different ways, depending on how they were induced to parse the display (subjective organization). In Experiments 1 and 2, the observers were asked to describe the location of a tilted target among a varying number of vertical or horizontal distractors. Subjective organization was induced by instructing observers to parse the display into either three horizontal regions (rows) or three vertical regions (columns). The position of the target was critical: location performance, as assessed by reaction time and errors, was consistently impaired at the locations adjacent to the boundaries defining the regions, producing what we refer to as the subjective boundary effect. Furthermore, the extent of this effect depended on whether the stimulus-driven and conceptually driven information concurred or conflicted. This made location information more or less accessible. In Experiment 1, the strength of objective grouping was a function of the proximity of the items (near or far conditions) and their orientation in a $6 \times 6$ matrix. In Experiment 2, the strength of objective grouping was a function of similarity of color (items were color coded by rows or by columns) and the orientation of the items in a $9 \times$ 9 matrix. The subjective boundary effect was more pronounced when the display promoted grouping in the direction orthogonal to that of the task (e.g., when observers parsed by rows but vertical distractors were closer together [Experiment 1] or color coded [Experiment 2] to induce global columns). In contrast, this effect decreased when the direction of both objective and subjective organizations was parallel (e.g., when observers parsed by rows and horizontal distractors were closer together [Experiment 1] or were color coded [Experiment 2] to induce global rows). A localization search task proved to be an ideal forum in which objective and subjective organizations interacted. We discuss how these results indicated that observers' performance in a localization task was determined by the interaction of objective and subjective organizations, and that the resulting perceptual organization constrained coarse location information.
\end{abstract}

There is general agreement that perceptual grouping occurs preattentively, and that this organization should affect subsequent stages of processing (e.g., Beck, 1966, 1967; Bravo \& Blake, 1990; Duncan, 1984; Duncan \& Humphreys, 1989; Julesz, 1980; Neisser, 1967; Prinzmetal \& Banks, 1977; Treisman, 1982; but see Barchilon Ben-Av, Sagi, \& Braun, 1992; Palmer \& Rock, 1994). Indeed, grouping has been found to play a role in both feature and conjunction searches (e.g., Bundesen \& Pedersen, 1983; Humphreys, Quinlan, \& Riddoch, 1989; McLeod, Driver, \& Crisp, 1988; Nakayama \& Silverman, 1986; Poisson \& Wilkinson, 1992; Treisman, 1982). Following perceptual-grouping principles such as similarity and proximity, visual search models claim that search is facilitated with greater targetdistractor discriminability and efficient grouping of ho-

This study was supported by a grant from the National Science Foundation (NYI Grant SBR-9357986) to M.C. I.C. was a Ford Foundation Fellow at Wesleyan University (Summer 1993). We would like to thank Asher Cohen and Arthur Kramer for their helpful comments, and Dimitra Theofanou for her assistance with data analysis. Correspondence regarding this paper should be addressed to $\mathrm{M}$. Carrasco, Department of Psychology, New York University, 6 Washington Pl., 8th Floor, New York, NY 10003-1055 (e-mail: marisa@xp.psych.nyu.edu). mogeneous distractors, but that it is hindered by grouping between target and distractors and by an increase in the number of different distractor groups (e.g., Duncan \& Humphreys, 1989, 1992; Farmer \& Taylor, 1980; Treisman \& Gormican, 1988; Wolfe, 1992, 1994; Wolfe, Cave, \& Franzel, 1989).

Likewise, the spatial layout of target and distractor items is an important factor in directing visual search; for instance, successful grouping by similarity-via color or orientation - is more effective when items are adjacent. For both feature search (Bundesen \& Pedersen, 1983; Farmer \& Taylor, 1980; but see Treisman, 1982) and conjunction search (Poisson \& Wilkinson, 1992; Treisman, 1982), arrays containing large regions of homogeneous distractors are searched faster than arrays in which items in the searched set are spatially intermingled with items of another distractor type.

The role of stimulus location in the selective processing of visual information has attracted much interest (e.g., Duncan, 1984; Kahneman \& Henik, 1981; Nissen, 1985; Sagi \& Julesz, 1985b; Treisman \& Gelade, 1980; Tsal, 1983). Although most research on visual search has involved detection, identification and localization processes have been more thoroughly explored recently. There is no consensus, 
however, as to whether we first perceive the identity of an object and then make a decision about its location, or whether we must first know where an object is in order to tell what it is. Questions about the difficulty of these two tasks, the degree of attention required to perform them, and their temporal order are all part of the "what and where" controversy (e.g., Atkinson \& Braddick, 1989; Green, 1992; Johnston \& Pashler, 1990; Sagi \& Julesz, 1985b; Treisman, 1993; Treisman \& Gelade, 1980).

According to some studies, for features to be identified, location information has to be available (e.g., Eriksen \& Rohrbaugh, 1970; Keele, Cohen, Ivry, Liotti, \& Yee, 1988; Sagi \& Julesz, 1985b; van der Heijden, 1993). Other studies, however, show that location information is poorly registered during the initial identification of features (e.g., Cohen \& Ivry, 1989, 1991; Estes, 1972; Ivry \& Prinzmetal, 1991; Prinzmetal \& Keysar, 1989; Wolford \& Shum, 1980), and that it is subject to rapid decay (e.g., Sperling, 1960; Wolford, 1975). Several models have addressed the quality of location information.

The feature perturbation model (Wolford, 1975; Wolford \& Shum, 1980) states that the migration of some features over time distorts the perceived relative location of various features. According to this model, under speeded presentations, performance is influenced by where the target is located, as well as by how many flanking distractors there are, and how close and how similar they are to the target. As retinal eccentricity increases, observers' performance decreases, and more so if a target is flanked by a peripheral distractor than if it is flanked by a foveal distractor. Identification performance is also affected by target-distractor discriminability.

The quality of location information available to the visual system is also reflected by illusory conjunctions - that is, by the incorrect perceptual combination of correctly perceived stimulus features such as color and shape (e.g., Treisman \& Schmidt, 1982). The effects of display density on visual search and on illusory conjunctions have suggested that two mechanisms are responsible for feature integration (Cohen \& Ivry, 1989, 1991). Whereas the first is fast and uses coarse location information to bind features into objects, the second is slower and is used when objects are located close to each other. Although features are generally perceived with coarse location information that is accurate enough to prevent confusion of features between distant objects, this information is not accurate enough to prevent confusion of features between adjacent objects. However, illusory conjunctions are a function not only of the distance among items in the display, but also of the way in which they are perceptually organized into coherent configurations or groups either by objective organization (proximity and similarity) or by subjective organization (Prinzmetal, 1981; Prinzmetal \& Keysar, 1989).

Some of the most interesting studies on perceptual organization illustrate that the percept depends not only on objective organization but also on subjective organization. A single figure can be subjectively organized into two different interpretations, even though the physical information received by the eye is the same. For instance, a given face of a Necker cube can appear in the background at one moment and in the foreground the next, but not hoth at the same time. Likewise, an ambiguous matrix of equally spaced aligned dots can be seen as either rows or columns. This ambiguity is diminished by manipulating the proximity or the similarity of the dots (Attneave, 1971).

Prinzmetal and Keysar (1989) capitalized on these phenomena. They found that illusory conjunctions occurred more often within than between groups induced by either the proximity of the items (objective physical information) or the way in which observers subjectively organized the display, via a primary reading task. These authors concluded that since the visual system integrates and combines visual information over surfaces and objects, location information of features may be blurred within an object or perceptual whole. Spatial resolution and location information for color, for example, may be poor within an object or structural unit. By filtering out the noise, a blurring or spreading of color within an object gives the impression that the object is more homogeneous and aids in a more economic form of coding.

The use of task instructions to induce observers' subjective organization represents a useful control in which the identical display can also be used to explore attentional demands of within- and between-object comparisons. Baylis and Driver (1993) found that with color instructions defining a perceptual set, observers were more successful at comparing the edges of what they perceived to be parts of the same object than they were at comparing what they perceived to be parts of different objects, even though the physical displays inducing the different interpretations were exactly the same. Similarly, Yantis (1992) has shown that visual tracking performance improved when observers were able to subjectively organize the items to form a coherent but not rigid virtual object.

Visual search models broadly refer to Gestalt grouping principles (Koffka, 1935; Wertheimer, 1923), without delving into when, where, and how they come into effect. They have neither systematically studied the effects of objective organization nor even considered the effects of subjective organization. Although "virtually all discussions of perceptual organization - from those of the Gestalt psychologists ... to those of recent psychologists ..., psychophysicists..., and computer-vision theorists...-have considered perceptual organization as an exclusively bottom-up or stimulus-driven phenomenon" (Yantis, 1992, p. 325), the three studies just discussed (Baylis \& Driver, 1993; Prinzmetal \& Keysar, 1989; Yantis, 1992), in conjunction with previous demonstrations of conceptually driven processes on perceptual organization (e.g., Attneave, 1971; Peterson \& Gibson, 1991; Peterson \& Hochberg, 1983), show that perceptual organization need not be entirely stimulus driven; the perceptual demands of a task that induce subjective organization of the display also affect perceptual organization.

We believe that both objective and subjective organizations could be powerful tools with which to advance our understanding of early visual processing. However, the effects of neither objective nor subjective perceptual group- 
ing on localization search performance have been studied. In this study, we investigated how subjectively defined regions would affect localization performance on a search task. Specifically, we explored the ways in which perceptual organization resulting from the interaction of objective organization and subjective organization affect observers' ability to localize a target. By implementing the visual search paradigm and working with such basic items as lines, it is possible to explore how observers might be induced to perceptually organize information in different ways as a by-product of different stimulus configurations and task instructions.

\section{EXPERIMENT 1}

The perceptual groups (rows or columns) induced by subjective and objective organizations either agreed or conflicted. We manipulated subjective organization by varying the instruction: observers were asked to localize a tilted target in terms of three regions composed of either rows or columns. We manipulated objective organization by varying the stimulus. Distractor orientation (vertical or horizontal) was manipulated in conjunction with the proximity (near vs. far spacing) of the stimuli to create displays that were rigged or weighted toward being grouped as a set of rows or a set of columns. Thus, the direction of the instruction was parallel or perpendicular to the global objective organization of the display. Given that the same stimuli were used for both row- and columnstimulus organizations, each display served as its own control; hence, any difference in performance could not be due to uncontrolled physical stimulus factors and could be attributed to subjective organization (Prinzmetal \& Keysar, 1989).

Homogeneous lines that are aligned without jitter naturally group to form a global line-good continuationespecially when the line segments are proximate (see near condition of Figure 1: the vertical lines group to form global columns). Increasing the space between these line segments weakens this grouping (Pomerantz \& Schwaitzberg, 1975), and allows an alternative one to take place. If spacing is sufficiently increased (see far condition of Figure 1), the vertical lines could just as easily form global rows. Search performance improves when distractors group strongly and are then rejected or inhibited as a unit (Duncan \& Humphreys, 1989, 1992); moreover, the time to search for a target increases with the number of gestalts that the distractors produce (e.g., Bundesen \& Pedersen, 1983; Farmer \& Taylor, 1980; Poisson \& Wilkinson, 1992).

On the basis of the idea that location information is coarsely coded (e.g., Cohen \& Ivry, 1989, 1991; Wolford, 1975; Wolford \& Shum, 1980) and constrained by perceptual grouping (Prinzmetal, 1981; Prinzmetal \& Keysar, 1989), we hypothesized that when the target was embedded in a global objective perceptual group, and observers were instructed to subjectively parse the display in the direction orthogonal to that of the objective grouping, localization performance would be impaired. Since the target's defining feature (orientation) would be blurred within
DISPLAYS FOR EXPERIMENT I

NEAR SPACING

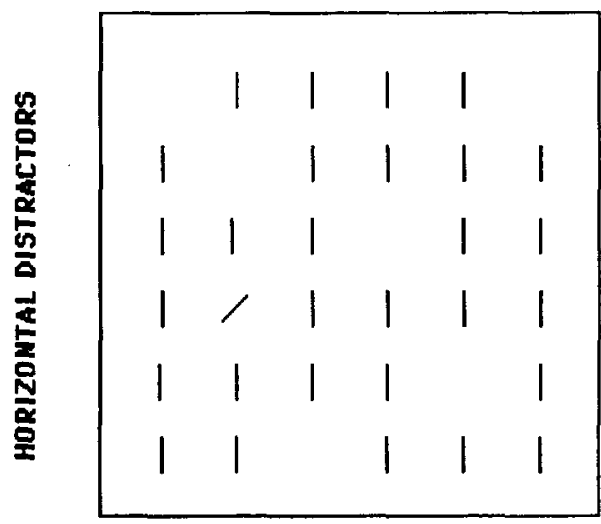

YERTICAL DISTRACTORS

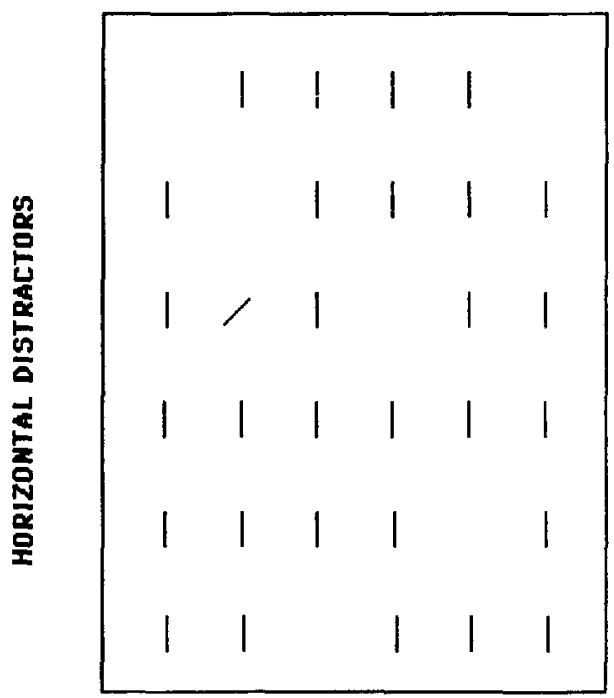

FAR SPACING

Figure 1. Display used in Experiment 1: Tilt page to view near and far conditions with both vertical and horizontal distractors.

its group, and its location information would not be readily accessible, observers would have to consider the items in the display with more scrutiny. In contrast, when the directions of the objectively and subjectively defined groups agreed, performance would be facilitated.

\section{Method}

Observers. Thirty Wesleyan University undergraduates participated in the experiment as a partial requirement for an introductory psychology course. All observers had normal or corrected-to-normal vision and were naive as to the purpose and method of the experiment.

Apparatus and Stimuli. The stimuli were presented in a darkened room on a high-resolution color monitor controlled by a Macintosh IIci microcomputer. The experimental program was created by VSearch software (Enns \& Rensink, 1991). The stimuli consisted of a red right-tilted target ( $+35^{\circ}$ from vertical), and horizontal and vertical blue distractors, against a red background. Each stimulus subtended $0.5^{\circ} \times 0.03^{\circ}$ (length $\times$ width) of visual angle. 
The items were arranged in a square matrix of six rows and six columns subtending a $6^{\circ} \times 6^{\circ}$ visual angle. There were two spacing conditions. In the near condition, interitem distance was measured from the midpoint of one item to the midpoint of another. This distance was equal in both vertical and horizontal directions $\left(1^{\circ}\right)$, but since the items were not square, the actual spacing between items was less between the endpoints than between the midpoints of the lines. For example, looking at Figure 1, it is easy to see how for vertical distractors, the vertical spacing is less than the horizontal spacing. In the far condition, the distance from endpoint to endpoint was equal to the distance from midpoint to midpoint. As a result, the spacing from midpoint to midpoint was $1^{\circ}$ in one direction, and $1.5^{\circ}$ in the other. The overall dimensions of the display measured $6^{\circ} \times 9^{\circ}$ (length $\times$ width) for the horizontal distractors and $9^{\circ} \times 6^{\circ}$ (length $\times$ width) for the vertical distractors.

Design. The experiment lasted $1 \mathrm{~h}$. There were eight experimental blocks, each of which consisted of 108 randomized trials. Each experimental block represented a possible interaction among distractor orientation (vertical or horizontal), spacing (near or far), and set sizes $(6,18,30$ or $12,24,36)$. The order of the blocks was counterbalanced among observers. The spacing between items, the orientation of the distractors, and the set sizes were independently manipulated from trial to trial. Observers began with two practice blocks of 108 trials each that allowed for exposure to all different set sizes, and to both distractor orientations and spacing conditions. The positions of the target and the distractors were randomized.

Procedure. The observers were told to fixate on the continuously visible fixation point $\left(0.07^{\circ}\right.$ of visual angle $)$ at the center of the screen. They were asked to localize the tilted target as quickly and as accurately as possible, since both their reaction time (RT) and error rates were to be recorded. Half of the observers were instructed to determine whether the target appeared in the two left, the two middle, or the two right columns (column instruction; to avoid confusion between the direction of the position analysis and the instructions, we refer to the latter in italics). The remaining observers were asked to judge whether the target appeared in the two top, the two middle, or the two bottom rows (row instruction). Right-handed participants indicated left, middle, right (column instruction) or bottom, middle, top (row instruction) by pressing the appropriate computer keyboard keys with the index, middle, and ring fingers, respectively. Left-handed participants were asked to use the reverse pattern of response keys. The display was presented for $105 \mathrm{msec}$; failure to respond within $1,050 \mathrm{msec}$ was considered an error.

\section{Results and Discussion}

General analysis. Figure 2 presents the observers' mean correct RT and error rate as a function of set size for the near and far conditions for both column and row instructions. Analyses of variance (ANOVAs) with one betweensubjects factor (instruction) and three within-subjects factors (spacing $\times$ distractor orientation $\times$ set size) were performed on the mean correct RT and mean percentage of error for each observer (Table 1). All results included here were significant $(p<.05)$, unless noted otherwise. All pairwise comparisons are Newman-Keuls $(p<.05)$.

The main effect of spacing was significant for RT (far $=$ $602 \mathrm{msec}$; near $=588 \mathrm{msec}$ ), but not for error $(\mathrm{far}=10 \%$; near $=9 \%$ ). The detrimental effect of increased spacing may be due to a weakening of perceptual grouping by decreased proximity (Pomerantz \& Schwaitzberg, 1975).

In addition, for both instructions, the target was processed faster and more accurately when it appeared among horizontal distractors than when among vertical distractors. Because the target-distractor discriminability was

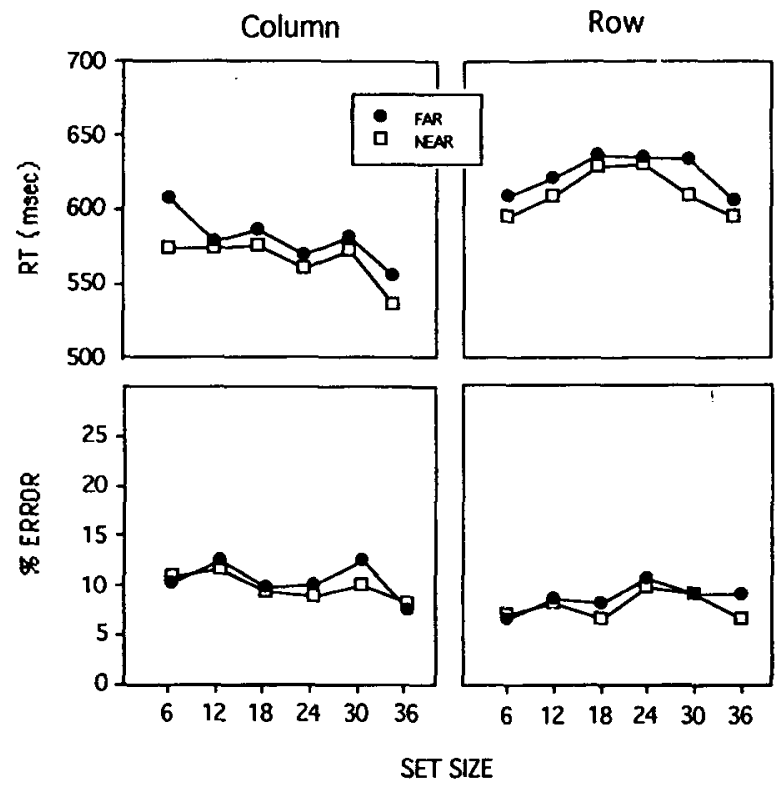

Figure 2. Observers' mean correct reaction times (RTs, in milliseconds) and error rates (in percentages) as a function of set size for near and far conditions under column and row instructions (Experiment 1).

lower when the target deviated from verticality than when it deviated from horizontality $\left(35^{\circ}\right.$ vs. $\left.55^{\circ}\right)$, localization performance was impaired. This finding is closely related to that of Bergen and Julesz (1983), who showed that detection of a target tilted at $45^{\circ}$ was faster than detection of a target tilted at $30^{\circ}$ among vertical distractors. Indeed, there is general agreement that feature search is driven by a parallel process that is capable of registering the entire display when target and distractor differences are clearly discernible. When these differences are less obvious, however, groups of items must be attended for the differences to become apparent (Duncan \& Humphreys, 1989; Quinlan \& Humphreys, 1987; Treisman, 1993; Treisman \& Gormican, 1988; Wolfe, 1994; Wolfe et al., 1989).

The main effect of set size was also significant, as was its interaction with instruction. In general, for column instruction (Figure 2, left panels), as set size increased, RTs and errors decreased. For row instruction (Figure 2, right panels), RTs and errors increased from small to medium set sizes, and then decreased again to the largest set size. According to the conventional criteria used to classify a search as being parallel or serial (e.g., Enns \& Rensink, 1990; Treisman \& Gormican, 1988), localizing a tilted target among vertical or horizontal distractors was performed in a parallel fashion (see General Discussion).

Analysis of target position. This analysis was conducted to determine whether the target position within the display influenced performance. Specifically, we explored whether particular combinations of instruction, spacing, and distractor orientation led to different distributions of RT and error data. We expected that it would be harder to localize the tilted target in the appropriate region when it 
Table 1

ANOVA Results for Experiment 1

\begin{tabular}{|c|c|c|c|c|c|}
\hline \multirow[b]{2}{*}{ Factor } & \multirow[b]{2}{*}{$d f$} & \multicolumn{2}{|c|}{ RT } & \multicolumn{2}{|c|}{ Error } \\
\hline & & $F$ & $p$ & $F$ & $p$ \\
\hline Instruction (I) & 1,28 & 1.90 & n.s. & $<1$ & n.s. \\
\hline Spacing (Sp) & 1,28 & 5.22 & $<.05$ & 2.66 & n.s. \\
\hline Orientation $(\mathrm{O})$ & 1,28 & 22.24 & $<.001$ & 12.78 & $<.005$ \\
\hline Column & 1,14 & 19.66 & $<.001$ & 1.92 & $<.001$ \\
\hline Row & 1,14 & 6.04 & $<.05$ & $<1$ & n.s. \\
\hline Set size (SS) & 5,140 & 13.13 & $<.001$ & 3.57 & $<.005$ \\
\hline $\mathrm{I} \times \mathrm{SS}$ & 5,140 & 9.43 & $<.001$ & 2.95 & $<.05$ \\
\hline Column & 5,70 & 14.15 & $<.001$ & 2.78 & $<.05$ \\
\hline Row & 5,70 & 9.11 & $<.001$ & 4.2 & $<.005$ \\
\hline $\mathrm{I} \times \mathrm{D} \times \mathrm{P}$ & 5,140 & 65.60 & $<.001$ & 38.69 & $<.001$ \\
\hline Column & 5,70 & 32.52 & $<.001$ & 32.33 & $<.001$ \\
\hline Row & 5,70 & 35.61 & $<.001$ & 12.31 & $<.001$ \\
\hline $\mathrm{Sp} \times \mathrm{O} \times \mathrm{D} \times \mathrm{P}$ & 5,140 & 4.32 & $<.005$ & 2.32 & $<.05$ \\
\hline \multicolumn{6}{|l|}{$\mathrm{Sp} \times \mathrm{P}$} \\
\hline \multicolumn{6}{|l|}{ Column } \\
\hline Horizontal columns & 5,70 & 2.57 & $<.05$ & 5.75 & $<.001$ \\
\hline Vertical columns & 5,70 & $<1$ & n.s. & $<1$ & n.s. \\
\hline \multicolumn{6}{|l|}{ Row } \\
\hline Horizontal rows & 5,70 & 1.05 & n.s. & 1.44 & n.s. \\
\hline Vertical rows & 5,70 & 3.23 & $<.05$ & 1.74 & n.s. \\
\hline
\end{tabular}

Note--D, direction of position analysis; $P$, target position in terms of columns or rows.

appeared in a row or column neighboring boundaries between the three regions imposed by the instructions-row or column, respectively.

To assess performance by target position, the correct RTs and frequencies of error per column and row, collapsed across set sizes, were subjected to ANOVAs with one between-subjects factor (instruction) and four withinsubjects factors (spacing $\times$ distractor orientation $\times$ direction of position analysis [column or row] $\times$ target position in terms of columns or rows [Position 1 was assigned to the leftmost column or the topmost row in the matrix, and Position 6 to the rightmost column or bottommost row]).

Two basic patterns were found in terms of target position: (1) a subjective boundary effect; and (2) an eccentricity effect. It is important to note that the perceptual groups in which these effects appeared were reversed for the two instructions.

Subjective boundary effect. Even though observers were presented with identical physical displays and the targets appeared in the same locations, instructing observers to localize in terms of columns or rows was sufficient to induce subjective organization of the field in the direction of the instruction. For column instruction (Figure 3a), pairwise comparisons showed that the extreme peripheral columns (Columns 1 and 6) were processed the fastest and most accurately, followed by the two central columns (Columns 3 and 4), with peaks in RT and errors occurring at the two columns bordering the imaginary, or subjective, boundaries dividing the center region from the peripheral left and right regions (Columns 2 and 5). In contrast, for row instruction (Figure $3 \mathrm{~d}$ ), the boundary effect was present for rows instead of for columns. Pairwise comparisons showed that the rows bordering the subjective boundary externally (Rows 2 and 5) were slower and less accurate than the two peripheral rows (Rows 1 and 6) and the two

\section{INSTRUCTION}

Column

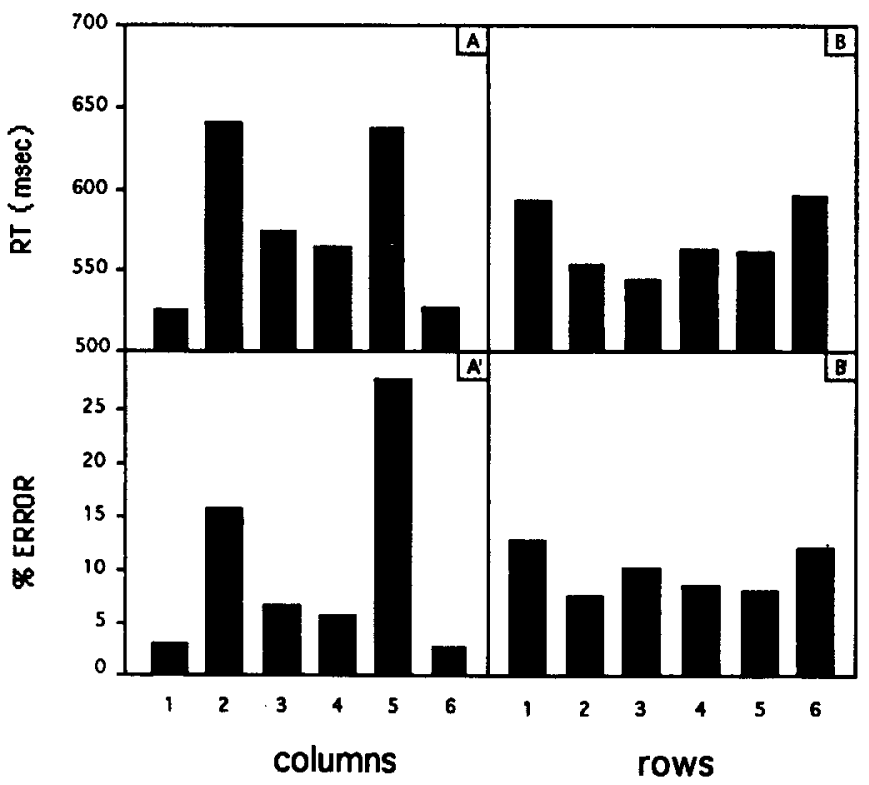

Row

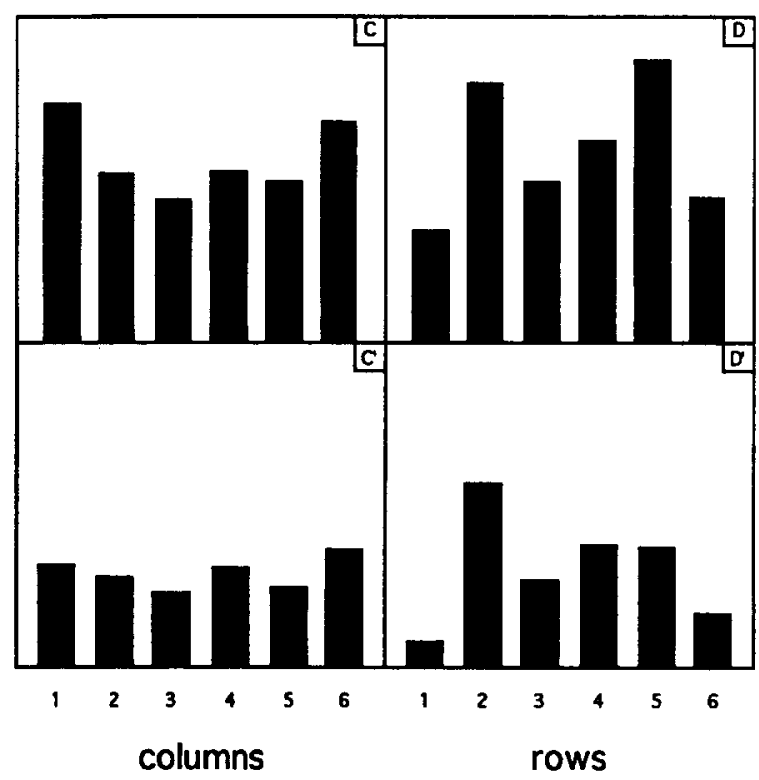

\section{POSITION}

Figure 3. Observers' mean correct reaction times (in milliseconds) and error rates (in percentages) as a function of the column or row the target appeared in, for column and row instructions (Experiment 1 ). $A$ and $D=$ subjective boundary effect; $B$ and $C=$ eccentricity effect. 
central rows (Rows 3 and 4). The three-way interactions of instruction $\times$ direction $\times$ position reflect these opposing patterns of results found with each of the instructions (Table 1). We will refer to these peaks of increased RT and errors occurring at the positions externally adjacent to the subjective boundaries as the subjective boundary effect.

Eccentricity effect. When position was analyzed in the direction perpendicular (columns or rows) to that of the instruction (rows or columns), pairwise comparisons showed that the target was processed most slowly when it appeared in the most peripheral rows or columns ( 1 and 6$)$ under row or column instructions, respectively (Figures $3 \mathrm{~b}$ and $3 c)$. Although errors did not differ significantly, they followed the same pattern as RT (Figures $3 b^{\prime}$ and $3 c^{\prime}$ ). We will refer to this U-shaped pattern as the eccentricity effect (see General Discussion).

Given that grouping strength decreases as the proximity between different items decreases (Pomerantz \& Schwaitzberg, 1975), we explored whether the grouping that naturally occurs between proximate lines of identical orientation would be reduced when the distance between distractors was increased. Furthermore, we investigated possible interactions of this subjective conceptually driven process and objective factors known to affect the strength of the grouping process. Indeed, in some conditions, the subjective boundary effect was enhanced, and in others, it was reduced. The following examples illustrate how distractor orientation and the Gestalt principle of proximity interacted with the direction of the localization task.

Given that location information for some features is blurred and summed across objects or perceptual groups (Prinzmetal \& Keysar, 1989), localization should be easier when the items were grouped in the same direction both subjectively - by instruction--and objectively - by proximity and similarity (distractor orientation and targetdistractor discriminability). This was an optimum condition in which the relevant information about location was preserved and the irrelevant information was filtered out. After all, observers were asked to report which group the target was located in, not where in a group it was located. Thus, we hypothesized that the subjective boundary effect would decrease when the directions of objective grouping and subjective grouping agreed. In fact, our results showed that this facilitation was obtained by either (1) or (2) below.

(1) Decreasing the distance between distractors whose orientation was parallel to the instruction. Figure 4 shows that there were shorter RTs and lower errors for the near conditions than there were for the far conditions at all positions for vertical distractors for column instructions (Figures $4 \mathrm{a}$ and $\left.4 \mathrm{a}^{\prime}\right)$ and for horizontal distractors for row instructions (Figures $4 \mathrm{~d}$ and $4 \mathrm{~d}^{\prime}$ ). For example, under the row instruction, observers presumably drew subjective boundaries along the direction of the rows. Thus, perceptual grouping by rows, attained when the horizontal distractors were in closer proximity within rows than within columns, allowed for summation of feature information within each row, and simplified the comparisons that needed to be made between the rows.
(2) Increasing the spacing between distractors whose orientation was perpendicular to instruction. For column instructions, far spacing improved performance for horizontal distractors and weakened the extent of the boundary effect (Figures 4b and 4b'). Conversely, for row instructions, far spacing aided performance for vertical distractors and reduced the boundary effect (Figures $4 c$ and $4 c^{\prime}$ ). For instance, for the column instruction, horizontal items that were close enough to group together promoted organization of rows, which was against the direction of the instruction. The far-spacing condition facilitated localization by columns by weakening this row organization and enhancing column organization; hence, observers not only did not have to counteract the perpendicular organization, they could also more easily group in the direction parallel to instruction.

In fact, the facilitatory effect of the far-spacing condition was powerful enough to reverse the effect of distractor orientation. Figure 5 illustrates that under row instruction, with far spacing, as compared with horizontal distractors, the target was more quickly and accurately localized among vertical distractors, and the boundary effect was reduced (Figures $5 \mathrm{~d}$ and $5 \mathrm{~d}^{\prime}$ ); in the near condition, the opposite had been true (Figures $5 \mathrm{c}$ and $5 \mathrm{c}^{\prime}$ ). Similarly, under column instruction, as compared with vertical distractors, the target was localized more efficiently among horizontal distractors and the boundary effect was weakened (Figures $5 b$ and $\left.5 b^{\prime}\right)$. This difference was more pronounced for the far condition than for the near condition (Figures $5 \mathrm{a}$ and $5 \mathrm{a}^{\prime}$ ).

Conversely, we hypothesized that the extent of the subjective boundary effect would increase when the directions of objective grouping and subjective grouping conflicted. Because membership in a group can camouflage an item and impair its detectability (e.g., Banks \& Prinzmetal, 1976; Prinzmetal \& Banks, 1977), grouping of the items perpendicular to the direction of the instruction should result in the loss of, or more difficult access to, pertinent location information. If objective stimulus factors are powerful enough to counteract the subjective organization induced by instruction, localization should be more difficult. Indeed, this hindrance was obtained by either (1) or (2) below.

(1) Increasing the distance between distractors whose orientation was parallel to the instruction. Figure 4 shows that localizing the tilted target among vertical distractors under column instructions (Figures $4 \mathrm{a}$ and $4 \mathrm{a}^{\prime}$ ) and among horizontal distractors under row instructions (Figures $4 \mathrm{~d}$ and $4 d^{\prime}$ ) was more difficult for the far-spacing conditions than it was for the near-spacing conditions. Increasing the distance may have weakened the grouping in the direction of instruction, while making organization in the opposite direction more likely.

(2) Decreasing the distance between distractors whose orientation was perpendicular to the instruction impaired the localization of the target-among horizontal distractors under column instructions (Figures $4 b$ and $4 b^{\prime}$ ) and among vertical distractors under row instructions (Figures $4 c$ and $4 c^{\prime}$ ). Decreasing the distance may have strengthened the grouping in the direction opposite to the instruction.

Comparisons of the extent of the subjective boundary effect were based on: (1) comparisons made between two con- 

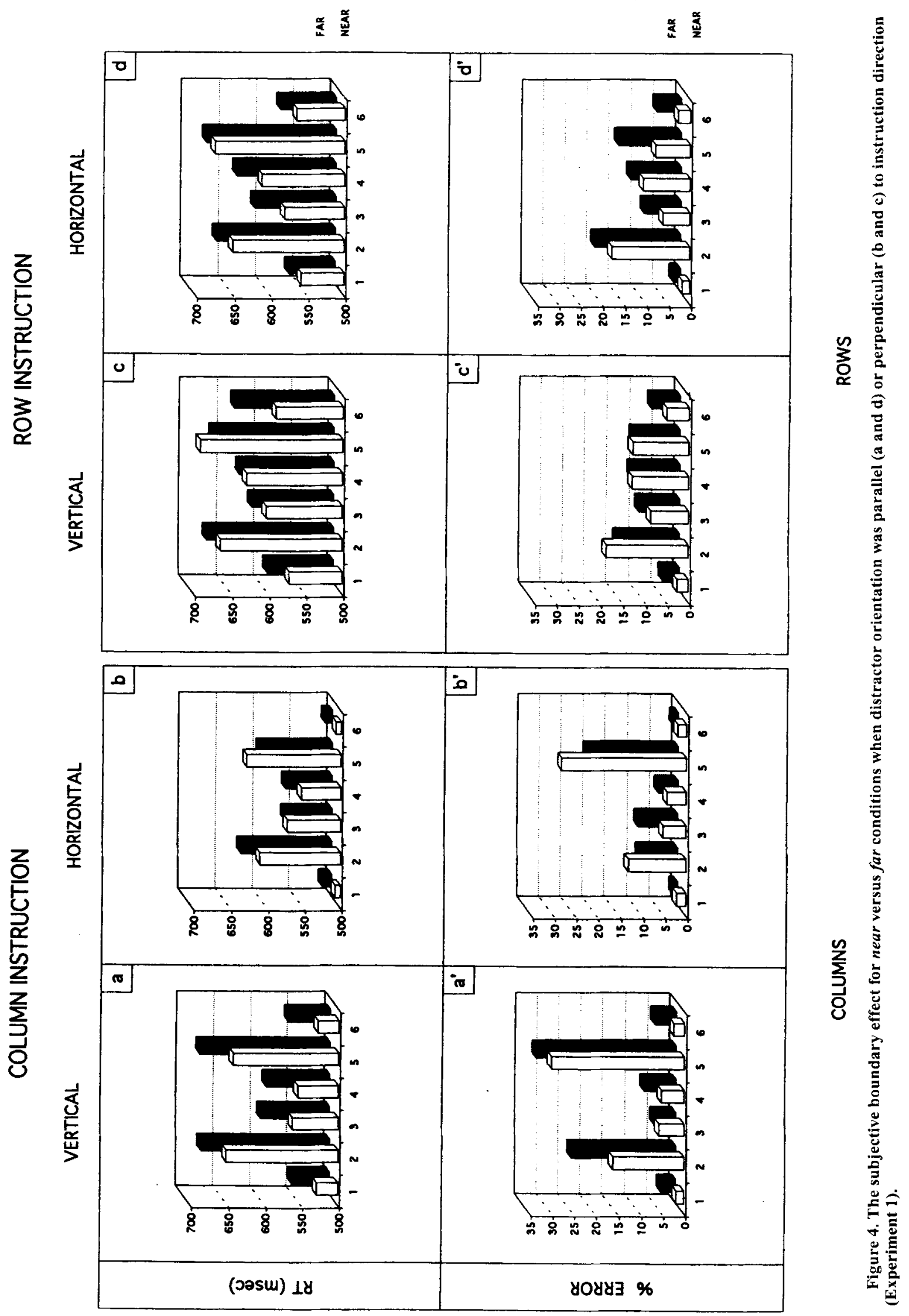


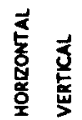

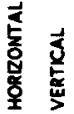

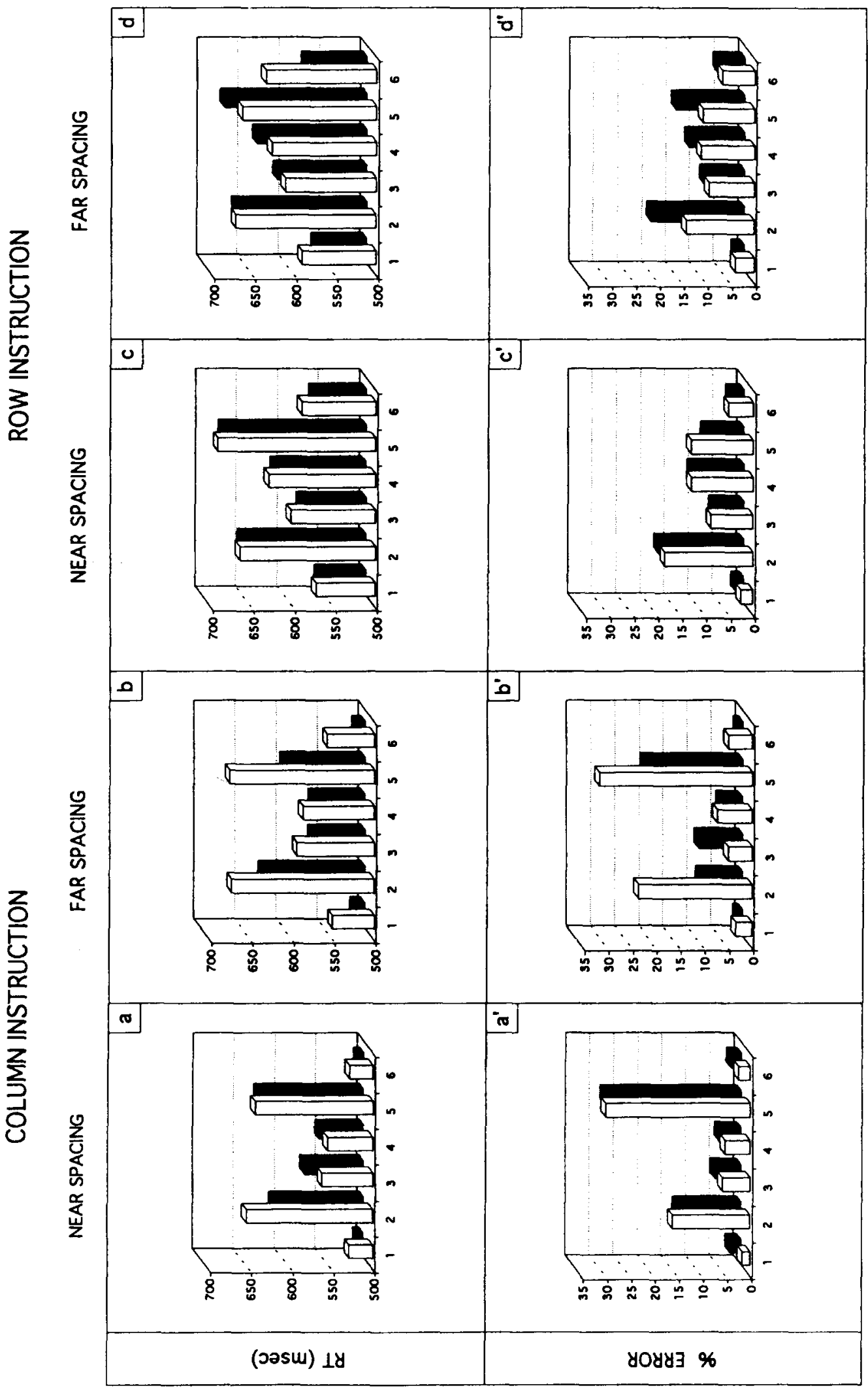


ditions (e.g., near vs. far) at the boundaries (Rows 2 and 5 for row instructions or Columns 2 and 5 for column instructions); and (2) comparisons made between the boundaries (Rows or Columns 2 and 5) and other positions (Rows or Columns $1,3,4$, and 6$)$ within a condition $(p<.05)$.

In sum, this subjective boundary effect was found with both near and far spacing of both homogeneous vertical and horizontal distractors. Objective organization was a function of the interaction of the proximity among items and distractor orientation. The main finding of this experiment is that the strength of perceptual grouping resulted from an interaction of this objective organization and the subjective organization induced by the localization task: Increasing the distance among items reduced the subjective boundary effect when the instruction direction and distractor orientation were perpendicular, and enhanced it when they were parallel.

\section{EXPERIMENT 2}

In this experiment, we further investigated how perceptual organization stemming from objective information interacts with the subjective organization induced by task instruction. We explored whether the findings of Experiment $l$ would be generalizable when objective grouping is brought about by a different Gestalt principle. Specifically, we examined how manipulating the similarity of the items in the display, via orientation and color, may interact with subjective organization and thus affect the strength of the subjective boundary effect. Gestalt theory has shown that by manipulating the proximity and the color similarity of stimuli, experimenters can create displays that "naturally" seem to group together (e.g., Banks \& Prinzmetal, 1976; Beck, 1982; Pomerantz, 1981). In addition, color coding the items in a display affects the degree of perceived similarity and reduces the time to locate a target in a visual scene (e.g., Banks \& Prinzmetal, 1976; Bundesen \& Pedersen, 1983; Eriksen, 1952, 1953; Hitt, 1961; Prinzmetal \& Banks, 1977). Furthermore, color is a property that is blurred across objects or groups, while at the same time it is constrained by perceptual organization (e.g., Prinzmetal \& Keysar, 1989). Given the effectiveness of color as a grouping inducer, we chose to use color to facilitate the organization of items into columns or rows, in such a way that the direction of perceptual organization by color could be neutral (monochromatic), in agreement with (parallel), or in opposition (perpendicular) to the orientation of the distractors, as well as to the direction of instructions.

In addition, we increased the size of the matrix from the $6 \times 6$ item display of Experiment 1 to a $9 \times 9$ item display to address two issues: First, in Experiment 1, performance deteriorated for the positions externally ( 2 and 5 ), but not internally ( 3 and 4 ), flanking the boundaries. Because we increased the number of columns and rows from 6 to 9 , the regions were defined not by pairs of columns and rows, but by trios. This allowed us to examine more precisely which locations would be affected by the subjective boundary, and to see whether performance was uniform for the central region, as was the case for Experi- ment 1 . Second, whereas the far-spacing condition used in Experiment 1 allowed us to manipulate proximity, it covaried with display size in such a way that spatial resolution may have affected the results; the larger the display, the lower the spatial resolution. Localizing a target in the far condition may have been more difficult because it is harder to make local comparisons of items over longer distances. To control for these possibilities, in this experiment, we induced grouping by color instead of by proximity. In Experiment 1, search was more difficult when the target tilted at $35^{\circ}$ than when it was tilted at $55^{\circ}$ from the vertical distractors. If target-distractor discriminability were responsible for this effect, the difference should disappear when observers searched for a tilted target that deviated equally from both vertical and horizontal distractors $\left(45^{\circ}\right)$.

\section{Method}

The stimuli, procedure, and design were the same as those of Experiment 1 , with the following exceptions.

Observers. A new group of forty Wesleyan undergraduates participated in a 90 -min experiment.

Apparatus and Stimuli. The experiment was run using VScope software (Micropsych Software; Rensink \& Enns, 1992), which enabled us to present the target at each of the 81 positions of the display in every single condition. Observers received feedback about their performance: a plus sign $(+)$ indicated a correct response, a minus sign ( -$)$ indicated an incorrect response, and $O$ indicated that no response was made before the maximum response time. The display subtended $9^{\circ} \times 9^{\circ}$ of visual angle. The right-tilted target was $45^{\circ}$. Owing to the size of the display, set sizes were increased to 40 , 60 , and 80 , so that $50 \%, 75 \%$, and $99 \%$ of the display was full.

The interitem distances corresponded to the near-spacing condition of Experiment 1. There were three color conditions: (1) monochromatic-all items in the display were blue, as in Experiment 1; (2) color by column - all items within a column were the same color; and (3) color by row-all items within a row were the same color. These color conditions were designed to encourage grouping by similarity. The three different color conditions allowed for neutral, parallel, and opposite organization of the items with respect to distractor orientation and instruction direction. All colors were of maximum brightness and saturation: RGB percentages correspond to those provided by the Macintosh custom color table: red: 100/0/0; orange: 100/50/0; yellow: 100/100/0; lime: 50/100/0; teal: 0/100/50; cyan: 0/100/100; blue: 0/0/100; purple: 50/0/100; magenta: 100/0/100.

Procedure. We included $10 \%$ absent trials (this percentage was not revealed to observers), to investigate whether observers in Experiment 1 had adopted a particular strategy based on their knowledge that the target would appear in every trial. One group of observers was instructed to determine whether the target appeared in the left three, middle three, or right three columns, or whether it was absent (column instruction); the other group of observers determined whether it appeared in the top three, middle three, or bottom three rows, or whether it was absent (row instruction). Observers used their thumb for keypresses indicating the target's absence.

\section{Results and Discussion}

General analysis. Figure 6 presents the observers' mean correct RT and error rates for present and absent trials as a function of set size for both column and row instructions. ANOVAs with one between-subjects factor (instruction) and four within-subjects factors (target $\times$ color condition $\times$ distractor orientation $\times$ set size) were performed on the correct-RT and on the error-percentage data (Table 2). 


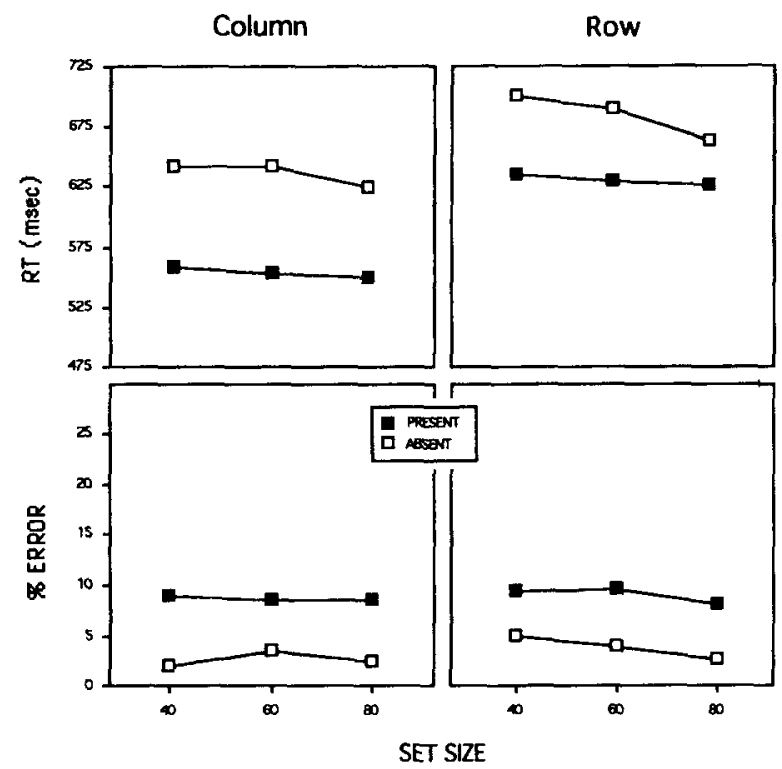

Figure 6. Observers' mean correct reaction times (RTs, in milliseconds) and error rates (in percentages) as a function of set size for present and absent targets under column and row instructions (Experiment 2).

Main effects indicated that RTs were faster for column than for row instructions, for present than for absent trials, and for larger than for smaller set sizes. Target $X$ instruction interacted because there was a greater difference between present and absent for column ( $553 \mathrm{vs} .636 \mathrm{msec}$ ) than for row ( $629 \mathrm{vs} .684 \mathrm{msec})$ instructions. The ease with which present targets were localized under column instructions seems to have been responsible for this interaction.

Although RTs were higher for absent than for present trials, there were more errors for the latter $(8.8 \%$ vs. $3.4 \%)$. This is a common finding in detection of both feature and conjunction tasks (e.g., Carrasco, Evert, Chang, \& Katz, 1995; Enns \& Rensink, 1990, 1991; Wolfe et al., 1989). This finding is not surprising, since absent trials represented a simple detection task, while present trials also required localization judgments. Whereas errors for absent trials reflect false alarms $(73 \%)$ or that observers took too long to respond $(27 \%)$, errors for present trials reflect misses $(8 \%)$, mislocalizations $(84 \%)$, or that observers took too long to respond $(8 \%)$. Errors were highest at Set Size 60 $(6.5 \%)$, and lowest at Set Size $80(5.5 \%)$. Given that performance improved at larger set sizes, the tilted target was localized in a parallel fashion (e.g., Enns \& Rensink, 1990; Treisman \& Gormican, 1988; see General Discussion).

As we hypothesized, the impairment of performance with vertical distractors in comparison with horizontal distractors found in Experiment 1 was eradicated when target-distractor discriminability was equated for both distractors by having a $45^{\circ}$ tilted target.

Analysis of target position. As in Experiment 1, the mean correct RT and frequency of error per target position were obtained for each observer. Since set size did not interact with any other factor, data were collapsed across set sizes. ANOVAs with one between-subjects factor (instruc- tion) and four within-subjects factors (color condition $x$ distractor orientation $\times$ direction of position analysis $\times$ target position) were performed on both RT and error rates.

Both of the main patterns found in the previous experiment were replicated in this experiment. For both RT and errors, the interactions of instruction $\times$ direction $\times$ position were significant (Table 2). The general pattern (direction $\times$ position) was highly consistent for column and row instructions. This pattern emerged for all three color conditions and for both orientations. As also revealed by pairwise comparisons, Figure 7 a shows that for column instruction, the peripheral columns were processed fastest (Columns 1 and 9), followed by the central columns of each region (Columns 2, 5, and 8), and that peaks occurred around the subjective boundary dividing the display into the three regions (Columns 3 and 4 and 6 and 7). In addition, Figure $7 a^{\prime}$ shows that these four boundary columns were processed less accurately than either the four most peripheral columns (Columns 1, 2, 8, and 9) or the central column (Column 5). Figure 7d illustrates that for row instruction, the boundary effect was present for rows instead of for columns. The peripheral rows (Rows 1 and 9) were fastest, followed by each region's middle rows (Rows 2, 5 , and 8 ), then by the internally flanking rows (Rows 4 and 6 ), with the externally flanking rows (Rows 3 and 7) having the highest RTs. Additionally, Rows 4 and 6 produced a greater number of errors than the peripheral rows (Rows 1 , 2,8 , and 9) and the central row (Row 5), followed by

Table 2

ANOVA Results for Experiment 2

\begin{tabular}{|c|c|c|c|c|c|}
\hline \multirow[b]{2}{*}{ Factor } & \multirow[b]{2}{*}{$d f$} & \multicolumn{2}{|c|}{ RT } & \multicolumn{2}{|c|}{ Error } \\
\hline & & $F$ & $p$ & $F$ & $p$ \\
\hline Instruction (I) & 1,38 & 14.21 & $<.001$ & $<1$ & n.s. \\
\hline Target $(\mathrm{T})$ & 1,38 & 113.13 & $<.001$ & 46.13 & $<.001$ \\
\hline Color (C) & 2,76 & 3.22 & $<.05$ & $<1$ & n.s. \\
\hline Orientation (O) & 1.38 & $<1$ & n.s. & $<1$ & n.s. \\
\hline Set size (SS) & 2,76 & 58.36 & $<.001$ & 7.6 & $<.001$ \\
\hline $\mathrm{I} \times \mathrm{T}$ & 1,38 & 4.60 & $<.05$ & $<1$ & n.s. \\
\hline Column & 1,19 & 65.78 & $<.001$ & 100.78 & $<.001$ \\
\hline Row & 1,19 & 47.54 & $<.001$ & 19.68 & $<.001$ \\
\hline $\mathrm{I} \times \mathrm{T} \times \mathrm{SS}$ & 2,76 & 4.10 & $<.05$ & 3.42 & $<.05$ \\
\hline Column & 2,38 & 6.25 & $<.005$ & 5.34 & $<.01$ \\
\hline Row & 2,38 & 22.68 & $<.001$ & 1.42 & n.s. \\
\hline $\mathrm{I} \times \mathrm{T} \times \mathrm{C} \times \mathrm{SS}$ & 4,152 & 4.51 & $<.005$ & 1 & n.s. \\
\hline Column & 4,76 & $<1$ & n.s. & $<1$ & n.s. \\
\hline Row & 4,76 & 7.42 & $<.001$ & 2.03 & $<.1$ \\
\hline $\mathrm{I} \times \mathrm{D} \times \mathrm{P}$ & 8,304 & 177.61 & $<.001$ & 79.22 & $<.001$ \\
\hline Column & 8,152 & 93.03 & $<.001$ & 50.13 & $<.001$ \\
\hline Row & 8,152 & 91.33 & $<.001$ & 36.68 & $<.001$ \\
\hline $\mathrm{I} \times \mathrm{C} \times \mathrm{O} \times \mathrm{D} \times \mathrm{P}$ & 16,608 & 1.55 & $<.1$ & 1.81 & $<.05$ \\
\hline Column & 16,304 & 2.13 & $<.01$ & 1.43 & n.s. \\
\hline \multicolumn{6}{|l|}{$\mathrm{O} \times \mathrm{D} \times \mathrm{P}$} \\
\hline Monochromatic & 8,152 & 2.47 & $<.05$ & 1.93 & n.s. \\
\hline Color by columns & 8,152 & 4.15 & $<.001$ & 2.22 & $<.05$ \\
\hline Color by rows & 8,152 & 1.62 & n.s. & 1.41 & n.s. \\
\hline Row & 16,304 & 2.06 & $<.01$ & 1.89 & $<.05$ \\
\hline \multicolumn{6}{|l|}{$\mathrm{O} \times \mathrm{D} \times \mathrm{P}$} \\
\hline Monochromatic & 8,152 & 3.35 & $<.005$ & 1.93 & n.s. \\
\hline Color by columns & 8,152 & $<1$ & n.s. & 1.08 & n.s. \\
\hline Color by rows & 8,152 & 3.18 & $<.005$ & 4.58 & $<.00 \mathrm{l}$ \\
\hline
\end{tabular}

Note-D, direction of position analysis; $P$, target position in terms of columns or rows. 


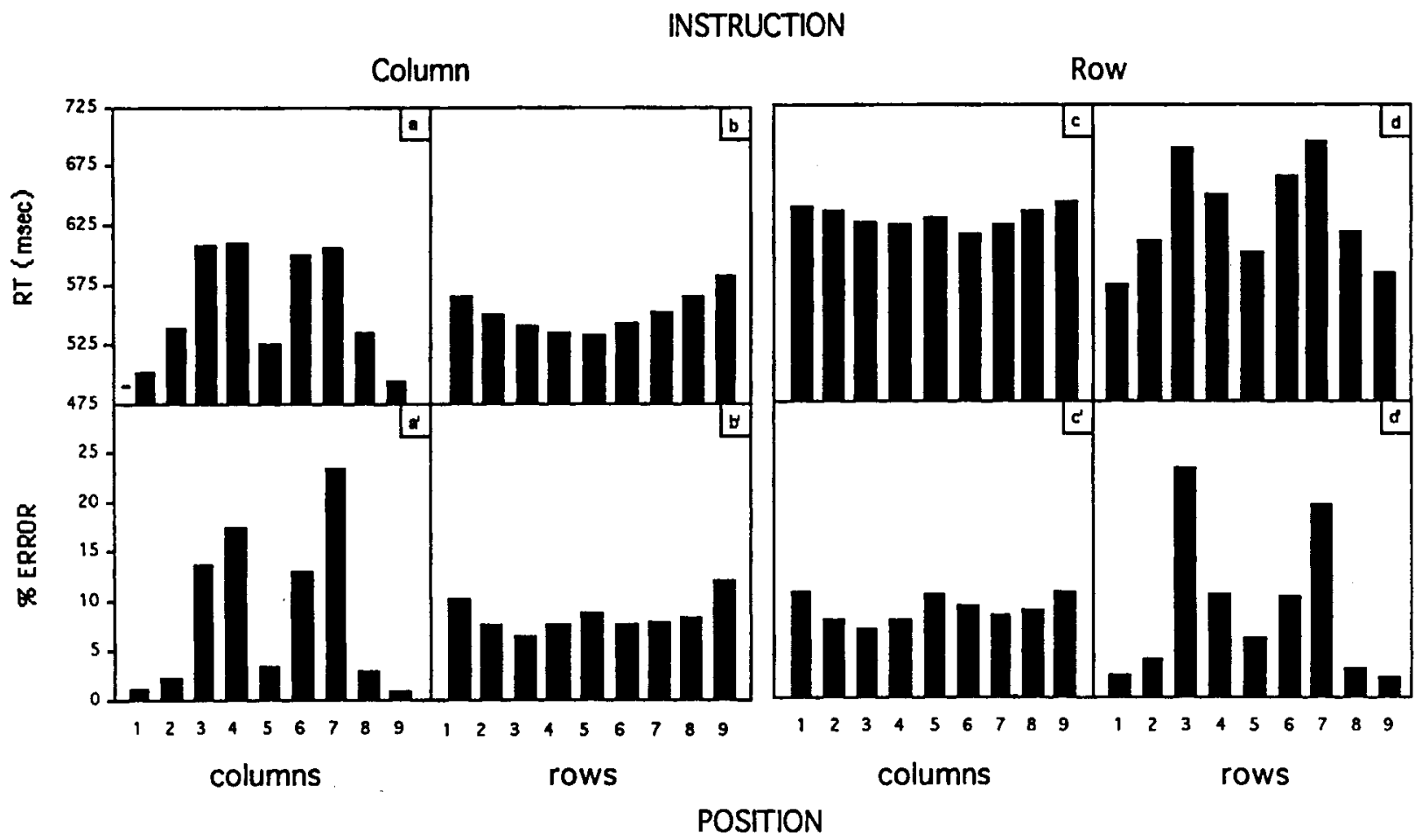

Figure 7. Observers' mean correct reaction times (RTs, in milliseconds) and error rates (in percentages) as a function of the column or row the target appeared in, for column and row instructions (Experiment 2 ). a and $d=$ subjective boundary effect; $b$ and $\mathrm{c}=\mathrm{ec}-$ centricity effect.

Row 7, with Row 3 acting as the most problematic row (Figure $\left.7 \mathbf{d}^{\prime}\right)$. This illustrates that the externally flanking rows were more difficult than the internally flanking rows.

In this experiment, performance decreased for both the internally and the externally bordering locations (Figure 7), whereas in Experiment 1, this subjective boundary effect was present only at the externally bordering locations (Figure 3). This difference may be related to the greater distance between the fixation point and the boundaries that divided the three regions, as well as to the greater number of both stimuli ( 81 vs. 36 ) and columns and rows ( 9 vs. 6 ) in the display; fewer frame references were available, and comparisons among items may have been more difficult. If observers compared the central fixation point and the outermost columns and rows to guide the parsing of the display, this experiment would be harder, especially when the target suffered from poor spatial resolution. The maximum distance from the fixation point to the farthest internally bordering positions subtended $2.55^{\circ}$ of visual angle in Experiment 1 and $4.12^{\circ}$ in Experiment 2. This substantial decrement in spatial resolution may have contributed to the decrement in observers' performance for the internally flanking positions in Experiment 2.

As we expected on the basis of the previous experiment, RTs followed a consistent but different pattern of results when position was analyzed perpendicularly to the direction of the instruction. In terms of rows for column instruction, pairwise comparisons indicated that RTs were faster at the center (Rows 3-6) than at periphery (Rows 1, 8, and 9;
Figure $7 \mathrm{~b})$. The error function was essentially flat; only the peripheral rows (Rows 1 and 9) induced more errors than the others (Figure $7 \mathrm{~b}^{\prime}$ ). Similarly, for row instruction, the outermost columns (Columns 1 and 9) had higher RTs than all other columns, leading to a predominantly flat function (Figures $7 \mathrm{c}$ and $7 \mathrm{c}^{\prime}$ ). The more pronounced eccentricity effect for column than for row instructions suggests that there is more of a gradient among rows than among columns. This finding, previously reported for detection tasks (Carrasco \& Katz, 1992), may correspond to the faster drop of spatial resolution in the vertical than in the horizontal direction (Curcio, Sloan, Packer, Hendrickson, \& Kalina, 1987; Rijsdijk, Kroon, \& van der Wilt, 1980).

In this experiment, the eccentricity and the boundary effects emerged consistently in all instruction, color, orientation, and set-size conditions. As we expected, observers' performance was affected by both subjective and objective factors, as well as by their interrelation. Instruction interacted with both color and orientation of stimuli. When the direction of all three factors coincided, the task was facilitated and the boundary effect reduced. The strong grouping by color similarity in the direction of the localization task helped chunk information, reduced the number of items that observers had to consider, and eased localization comparisons among groups, but hindered distinctions within a group.

As we hypothesized, objective grouping resulted from an interplay of distractor orientation and color coding; when they were in the same direction (e.g., when they were 
vertical distractors and were color coded by columns), they were expected to have a more pronounced effect on the extent of the subjective boundary effect than when they were in opposite directions (e.g., when they were vertical distractors but were color coded by rows). For each instruction, the effect of distractor orientation on the extent of the subjective boundary effect varied for the three different color conditions. This was revealed by the three-way interaction of orientation $\times$ direction of position analysis $\times$ target position, which had varying significance levels for the three different color conditions (Table 2). For column instruction, this interaction was significant for color by columns, was less significant for the monochromatic condition, and was not significant for color by rows. In the color-by-column condition (Figures $8 \mathrm{a}$ and $8 \mathrm{a}^{\prime}$ ), the effect of position was more pronounced for horizontal than for vertical distractors, as revealed by simple effects of the orientation $\times$ position interaction. Moreover, even though RTs were marginally slower for the vertical than for the horizontal distractors at the central column (Column 5) and the two peripheral columns (Columns 1 and $9 ; p<.10$ ), performance was faster and more accurate for vertical than for horizontal distractors at the flanking columns (Columns 3 and 6), thus creating a more pronounced subjective boundary effect for horizontal than for vertical distractors.

Conversely, for row instruction, orientation $\times$ direction $\times$ position was significant for color by rows and for the monochromatic condition, but not for color by columns. In the color-by-row condition, performance was faster for horizontal than for vertical stimuli at Rows 3, 4, and 7 (Figure 8b); performance was also more accurate for the horizontal than for the vertical stimuli at Row 7 (Figure $8 b^{\prime}$ ). Although for RTs, orientation $\times$ direction $\times$ po-

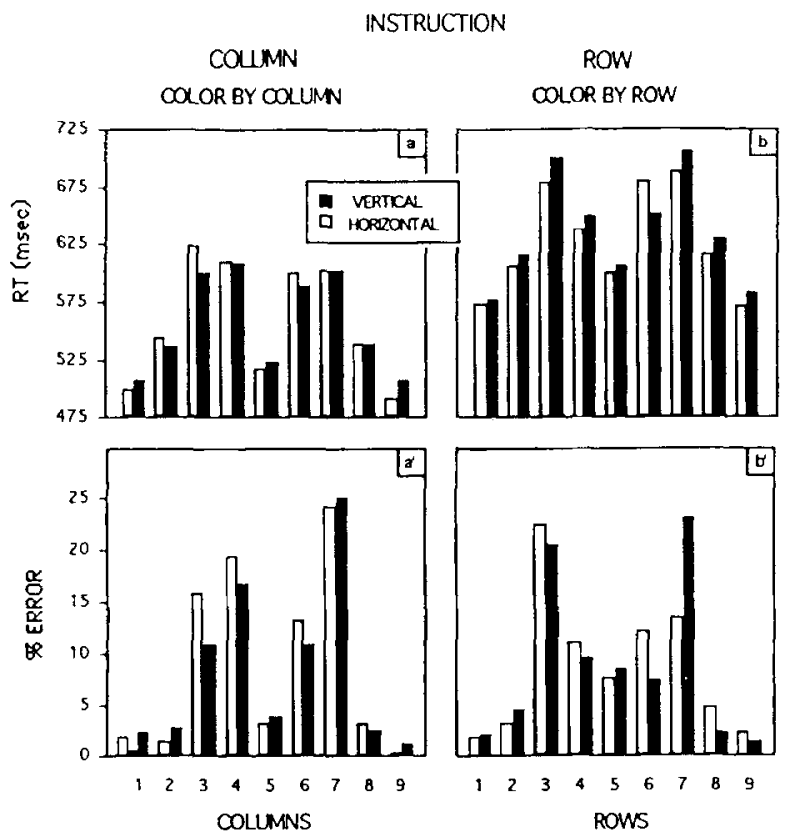

Figure 8. The subjective boundary effect for vertical versus horizontal distractors when items were color coded in the direction parallel to that of the instruction (Experiment 2). sition interacted for both instructions of the monochromatic condition, the effects of orientation did not follow a consistent pattern. In short, the facilitatory effect of having the orientation of the distractors parallel to the direction of the instruction was only significant if the direction of the color coding was also in agreement with instruction.

Under column instruction, the columns flanking the boundary both internally (Columns 4 and 6 ) and externally (Columns 3 and 7) were equally difficult in terms of RT and slightly harder for the externally flanking columns (607 msec and $55 \%$ out of total errors) than for the internally flanking columns $(605 \mathrm{msec}$ and $45 \%$; Figures $7 \mathrm{a}$ and $\left.7 a^{\prime}\right)$; for row instruction, however, the externally flanking rows were processed more slowly $(695 \mathrm{msec})$ and less accurately ( $69 \%$ out of total errors) than were the internally flanking rows (658 $\mathrm{msec}$ and $31 \%$; Figures $7 \mathrm{~d}$ and $\left.7 \mathrm{~d}^{\prime}\right)$.

In Prinzmetal and Keysar's (1989) study, observers were more likely to perceive an ambiguous matrix of squares as organized into columns than into rows. This finding, originally reported by Wertheimer (1923), corresponds to the biologically based low-pass band-filtered images of this matrix (Ginsburg, 1984, 1986). In Prinzmetal and Keysar's study, for observers to perceive the display as evenly organized, interrow distances had to be larger than intercolumn distances (we refer to this finding as the column-grouping bias). Accordingly, in the present experiments, observers may have perceived the distance to be smaller between rows than between columns and, thus, the global display as a horizontal rectangle rather than a square. Thus, under the row instruction, observers' incorrect localization of the targets appearing in the externally flanking rows as being in the central region may have resulted from an expanded representation of the central region. In addition, because spatial resolution decreases faster along the vertical than along the horizontal retinal axes (Curcio et al., 1987; Rijsdijk et al., 1980), the representation for rows may be fuzzier than that for columns. Furthermore, because observers fixated at the central fixation point during the display duration, their localization judgments may have been from the inside out. In short, observers may have assigned subjective boundaries around the area they considered to be the middle region, which, according to the column-grouping bias, would encompass more rows than columns. Indeed, more externally flanking rows than externally flanking columns were included in the central region $(55.1 \%$ vs. $69.2 \%)$.

In accordance with Prinzmetal and Keysar's (1989) theory, we found that location information for features was in some way constrained by perceptual organization. First, our findings support the idea that groups of items resulting from similarity in color may be treated as units (Banks \& Prinzmetal, 1976; Bundesen \& Pedersen, 1983; Kahneman \& Henik, 1977; Prinzmetal \& Banks, 1977). Second, the strength of perceptual grouping was a function of the interaction of color and orientation of the stimuli, even when proximity was constant. Third, and most important for our purposes, this objective perceptual grouping greatly influenced the extent of subjective organization resulting from task-specific instructions. 


\section{GENERAL DISCUSSION}

\section{General Localization Performance}

As mentioned in the Introduction, there is no consensus as to the degree of attentional involvement required for a localization task to be carried out (e.g., Atkinson \& Braddick, 1989; Green, 1992; Johnston \& Pashler, 1990; Sagi \& Julesz, 1985b; Treisman \& Gelade, 1980). A parallel search is defined as one in which no additional time is required as the number of distractors increases (e.g., Egeth, Folk, \& Mullin, 1989; Treisman \& Gelade, 1980). Overall, the localization task of the tilted target had a negative slope, and would thus be considered to have been conducted in a parallel fashion (e.g., Enns \& Rensink, 1990; Treisman \& Gormican, 1988). Our results agree with findings that observers perform localization tasks in parallel (Sagi \& Julesz, 1985b), and that increasing set size improves detection (Sagi, 1990). With the largest set size for both experiments ( 36 for Experiment 1 and 80 for Experiment 2), observers were able to detect a local difference signal where a relevant break or interrupt signal in the feature gradient existed (e.g., Johnston \& Pashler, 1990; Sagi \& Julesz, 1985a, 1985b).

\section{Localization Performance According to Target Position and Spatial Layout}

Two perceptual effects were consistently found throughout all the experimental manipulations of this study. First, when performance was assessed in terms of objective groups opposite to those of instruction, the position effect emerged: performance dropped as target eccentricity increased. This is the first time that the eccentricity effect was explored in a localization task (Experiment 1) and a simultaneous detection and localization task (Experiment 2). This effect, which has been previously reported in detection (Carrasco \& Katz, 1992; Carrasco et al., 1995) and identification (Carrasco \& Girard, 1993) tasks, seems to be explained by decreasing spatial resolution at greater retinal eccentricities.

Second, and most important for our purposes, both latency and accuracy performance reflected a very strong subjective boundary effect. Localization performance was impaired at the subjective boundaries defining the regions relevant for the task. This effect appears to be a prevalent perceptual phenomenon. It consistently emerged in all conditions we explored, when (1) the task consisted simply of localizing or of detecting and localizing the target, (2) the display subtended $6^{\circ} \times 6^{\circ}, 6^{\circ} \times 9^{\circ}$, or $9^{\circ} \times 9^{\circ}$ of visual angle, (3) the display consisted of set sizes $6-36$ or $40-80$, and (4) the target's orientation deviated from distractor orientation $\left(35^{\circ}\right.$ and $55^{\circ}$ or $\left.45^{\circ}\right)$. The subjective boundary effect was also obtained in a previous study conducted in our laboratory (Carrasco \& Girard, 1993), in which the target was horizontal or tilted $\left(+35^{\circ}\right.$ or $\left.-35^{\circ}\right)$ and the distractors were always vertical.

Our subjective boundary effect is not only in accordance with research involving the effect of spatial resolu- tion and coarse location information on feature perturbations and illusory conjunctions (Cohen \& Ivry, 1989; Estes \& Wolford, 1971; Wolford, 1975; Wolford \& Shum, 1980 ); by introducing the important role of subjective organization, our findings have actually added a dimension to the perceptual organization principles that traditionally have been considered to constrain spatial resolution (Banks \& Prinzmetal, 1976; Prinzmetal \& Banks, 1977; Prinzmetal \& Keysar, 1989).

There is evidence that the overall organization of the display may result from a fast but crude analysis of the scene, which contains coarse location information carried out by low spatial frequencies (e.g., Kinchla, 1977; Ginsburg, 1984, 1986). This coarse location information may be responsible for the fact that in both experiments, the mislocalizations always occurred between neighboring regions. This is in line with the finding that illusory conjunctions occur more often between adjacent items than between nonadjacent items (Cohen \& Ivry, 1989; Ivry \& Prinzmetal, 1991; Keele et al., 1988; Prinzmetal \& Keysar, 1989; Wolford \& Shum, 1980). When features are registered, the location information is coarse or incomplete. Whereas this location information is sufficient to prevent the confusion of features between distant objects, it is not accurate enough to prevent the migration of features between adjacent objects (Cohen \& Ivry, 1989; Prinzmetal \& Keysar, 1989).

The feature perturbation model provides more specific detail about the way in which lateral interference distorts information about the relative location of features. When a target is flanked by distractor items, its features are likely to migrate, especially when the target has poor spatial resolution (Wolford, 1975; Wolford \& Shum, 1980). In our experiments, when observers mislocalized the target, they reported that it appeared in the neighboring subjectively defined region. The findings that the boundary effect was present for the externally flanking locations (Locations 2 and 5) but not for the internally flanking locations (Locations 3 and 4; Experiment 1 ) and that for row instruction, localization performance was worse for the external than for the internal flanking rows (Experiment 2) may be explained by three central assumptions of the perturbation model: (1) there are more perturbations as distance from the fovea increases; (2) migrations are more likely toward the fovea than toward the periphery; and (3) the representation quality is affected by proximity and number of items flanking the target, this lateral interference being greater in the periphery than in the fovea (Estes \& Wolford, 1971; Wolford, 1975; Wolford \& Shum, 1980). Thus, although there was poor spatial resolution for targets placed at peripheral positions (Locations 1 and 6, Experiment 1; Locations 1 and 9, Experiment 2), they were processed rapidly and accurately because they only had internal flanking neighbors, which in any case belonged to the same region. The column-grouping bias (Ginsburg, 1986; Prinzmetal \& Keysar, 1989) that we addressed in the Discussion section of Experiment 2, may explain why for the col- 
umn instruction of Experiment 2, localization was not more impaired for the external, in comparison with the internal, flanking columns.

\section{Objective and Subjective Organizations Constrain Spatial Resolution}

Spatial resolution for an item decreases not only as retinal eccentricity increases (e.g., Hubel \& Wiesel, 1979), but also as its grouping with other items is strengthened (Banks \& Prinzmetal, 1976; Prinzmetal \& Banks, 1977; Prinzmetal \& Keysar, 1989). Although at the global level of analysis, the local identity of each item may be lost, the information signaling its membership of the group is preserved (e.g., Treisman, 1982). Thus, spatial resolution is constrained by perceptual organization, and apparent homogeneity is achieved by preserving less information within a group.

Moreover, it has been found that there is a two-way interaction between gestalt organization and spatial distortion: gestalt organization-via proximity, similarity, closure, or good continuation - may indeed distort the spatial relationships perceived in the field; in turn, this spatial distortion may enhance the already-existing grouping effect. The direction of the distortions seems to support the perceptual group; the distance between different items considered to be part of the same group is underestimated when compared with the distance between items considered to be part of different groups (Coren \& Girgus, 1980). According to the perturbation model (Wolford, 1975; Wolford \& Shum, 1980) and to density effects on illusory conjunctions (Cohen \& Ivry, 1989), the greater the separation between the target and the distractors, the less the interference (see also Collins \& Eriksen, 1967). Hence, this two-way interaction suggests that the similarity attained by the orientation of the distractors that formed a global unit influenced the perceived proximity of the items in the display, which in turn strengthened the grouping effect. Our experiments added a new variable to this equationnamely, subjective organization. The net perceptual grouping was a result of both gestalt grouping and subjective organization. We conclude that subjective organization must be considered as a factor that affects not only the strength of grouping among items, but also their perceived proximity or density, which in turn would influence the difficulty of target processing.

The results from our localization search task support Prinzmetal and Keysar's (1989) assertion that perceived organization of a display may constrain or limit location information, and that location information for some features is blurred across surfaces and within perceptual groups. What is key in our study is that within and across experiments, different aspects of the interaction of both objective and subjective organizations of the display were explored. We asked our observers to localize a target in terms of the subjective regions; they had to subjectively group the target with the distractors in either the same row or the same column. In contrast to Prinzmetal and Keysar's primary reading task, in which the physical cues (the digits that flanked the display) introduced a data-driven pro- cess, the subjective organization in this study resulted solely from a conceptually driven process via instructions. This finding corroborates the assertion that the demands of a task can organize the display in such a way that perceptual organization is not only the result of stimulusdriven processes (Baylis \& Driver, 1993; Yantis, 1992).

The conditions in which the subjective boundary effect was either enhanced or reduced as a function of objective perceptual grouping illuminate the processes underlying the boundary effect. Localization performance depended on whether the target was objectively grouped in the same direction or in the opposite direction to that of the instruction. The effects of proximity (Experiment 1) and color (Experiment 2) were a function of the relationship between distractor orientation and instruction. For instance, for column instruction, the far spacing between (Experiment 1 ) and color by row of (Experiment 2) vertical distractors impaired performance by diminishing the natural tendency of proximate vertical lines to be organized into columns: the peaks in RT and error rates at the subjective boundaries increased. Performance decreased because the subjective grouping required for the localization task had to overcome the objective grouping. It was harder to appropriately localize a target when the physical stimulus properties were powerful enough to influence the observer to organize the display in the direction opposite to the instructions, especially if it fell near the boundaries that defined the regions of the task. In this case, the location information that was pertinent to the task took longer to be accessed, and was often incorrect. Because location information for certain features can be efficiently and economically coded when constrained by perceptual organization, once blurring of information has occurred, there is an accompanying risk of losing pertinent information if the task requires more precise distinctions to be made within a perceptual group. It is as if the target were camouflaged by its membership in a group, making it more difficult to be detected, even when the proximity of the target to the items with which it was grouped was not greater than the target's proximity to other neighboring items with which it was not grouped.

On the other hand, when this same display was viewed by an observer under row instruction, the increase in spacing (Experiment 1) and color in the same direction as instruction (Experiment 2 ) was beneficial. Not only was the opposing organization weakened, but grouping by rows was also encouraged, thus reducing the subjective boundary effect. In fact, we succeeded in eliminating the subjective boundary effect by color coding the three regions that were imposed by the instructions of the localization task, in such a way that each region had a homogeneous color. For the column instruction, when the vertical regions were homogeneously coded, observers' performance in localizing the tilted target among vertical distractors did not differ across all nine columns. ${ }^{1}$ In this way, the present study provides evidence for the notions that the more integrated an item is to its group, the harder it is to detect (Banks \& Prinzmetal, 1976; Prinzmetal \& Banks, 1977), and that perceived grouping between target and dis- 
tractors in a display is harmful, while perceptual grouping among distractors is beneficial (Bundesen \& Pedersen, 1983; Duncan \& Humphreys, 1989, 1992; Farmer \& Taylor, 1980; Poisson \& Wilkinson, 1992).

Our results show that the way in which location information for colors is constrained by perceptual organization (Ivry \& Prinzmetal, 1991; Prinzmetal \& Keysar, 1989) may be true for orientation as well. The finding that the effects of proximity and color similarity were amplified by distractor orientation illustrates that Gestalt grouping principles should not be considered as simple, separate laws, but rather must be considered in relation to one another (e.g., Coren \& Girgus, 1980; Ginsburg, 1986). If location information for orientation is summated or integrated within an object, it follows that when perceptual organization is orthogonal to the instruction direction, localization decisions become more difficult, especially when the target appears close to the subjective boundaries. According to the grouping-strength model (Duncan, 1984), a preattentive segmentation of the visual field is followed by a more intensive analysis of a limited number of groups or perceptual units, which vary in the degree to which their items cohere. However, the question as to how different attributes combine to determine net perceived grouping calls for further work (Duncan \& Humphreys, 1992). Moreover, although the grouping of distractors by proximity and similarity of color has been established, the way in which such grouping is utilized in the search process has not been specified (Banks \& Prinzmetal, 1976; Bundesen \& Pedersen, 1983; Farmer \& Taylor, 1980; Treisman \& Gelade, 1980).

We concur with authors who state that the visual system's ability to organize visual items into perceptual objects is a fundamental aspect of visual selection, and that comprehensive theories of vision and visual attention require a satisfactory account of perceptual organization (Prinzmetal \& Keysar, 1989; Yantis, 1992). Moreover, we stress that perceptual organization results from an interplay of both objective, stimulus-driven factors and subjective, conceptually driven factors. Indeed, the subjective boundary effect illustrates how strongly task instructions influence visual processing and performance. Hence, it is important to explore the implications that task demands may have on different phenomena. For instance, regarding the localization-versus-identification search debate mentioned in the Introduction, it has been shown that the apparent order of these two processes may be affected by the level of precision necessary to perform the tasks (e.g., Atkinson \& Braddick, 1989) and by the target-distractor discriminability (e.g., Carrasco \& Girard, 1993). These factors, in turn, could be influenced by the way in which the subjective organization imposed by the task demands may affect the perceptual organization of the display. For instance, when observers are asked to localize the target by parsing the display in a certain fashion, the presence of subjective boundaries would impair performance.

To conclude, our localization task pitted stimulus-driven organization of the display against the conceptually driven subjective organization of the observers. Our success in enhancing and reducing the subjective boundary effect through manipulations of stimulus-driven perceptual grouping helps reveal how the interaction of objective organization and subjective organization determines perceptual organization. When observers are asked to perform a localization task that requires subjective organization, it is clear that the degree to which Gestalt grouping laws can facilitate or impede such parsing depends on the interactions of a multiplicity of stimulus factors, such as orientation and proximity (Experiment 1 ) or color (Experiment 2). The interaction between the two types of organization could be either beneficial or detrimental to performance: When objective and subjective organizations were in agreement, the two forces worked together in harmony and performance improved; when the two conflicted, however, the observers had to mediate between the two opponent forces, and their performance suffered as a result.

\section{REFERENCES}

Atkinson, J., \& Braddick, O. J. (1989). 'Where' and 'what' in visual search. Perception, 18, 181-189.

AtTnEave, F. (1971, December). Multistability in perception. Scientific American, 225, 62-71.

Banks, W. P., \& Prinzmetal, W. (1976). Configurational effects in visual information processing. Perception \& Psychophysics, 19, $361-367$.

Barchilon Ben-Av, M., SaGi, D., \& Braun, J. (1992). Visual attention and perceptual grouping. Perception \& Psychophysics, 52, 277-294

Baylis, G.C., \& Driver, J. (1993). Visual attention and objects: Evidence for hierarchical coding of location. Journal of Experimental Psychology: Human Perception \& Performance, 19, 451-470.

BECK, J. (1966). Effect of orientation and of shape similarity on perceptual grouping. Perception \& Psychophysics, 1, 300-302.

Beck, J. (1967). Perceptual grouping produced by line figures. Perception \& Psychophysics, 2, 491-495.

BECK, J. (1982). Textural segmentation. In J. Beck (Ed.), Organization and representation in perception (pp. 285-318). Hillsdale, NJ: Erlbaum.

Bergen, J. R., \& Julesz, B. (1983, June 23). Parallel versus serial processing in rapid pattern discrimination. Nature, 303, 696-698.

Bravo, M.J., \& Blake, R. (1990). Preattentive vision and perceptual groups. Perception, 19, 515-522.

Bundesen, C., \& Pedersen, L. F. (1983). Color segregation and visual search. Perception \& Psychophysics, 33, 487-493.

Carrasco, M., Evert, D. L., Chang, I., \& Katz, S. M. (1995). The ec centricity effect: Target eccentricity affects performance on conjunction searches. Perception \& Psychophysics, 57, 1241-1261.

Carrasco, M., \& Girard, D. D. (1993). On identification and location in visual search. Proceedings \& Abstracts of the Annual Meeting of the Eastern Psychological Association, 64, 29.

Carrasco, M., Katz, S. M. (1992). Feature asymmetries in visual search: Effects of display duration and target position. Proceedings and Abstracts of the Annual Meeting of the Eastern Psychological Association, 63, 25.

CoHEN, A., \& IVRY, R. B. (1989). Illusory conjunctions inside and outside the focus of attention. Journal of Experimental Psychology: Human Perception \& Performance, 15, 650-663.

Cohen, A., \& IVRY, R. B. (1991). Density effects in conjunction search: Evidence for a coarse location mechanism of feature integration. Journal of Experimental Psychology: Human Perception \& Performance, 17, 891-901

Collins, J. F., \& Eriksen, C. W. (1967). The perception of multiple simultaneously presented forms as a function of foveal spacing. Perception \& Psychophysics, 2, 369-373.

Coren, S., \& Girgus, J. S. (1980). Principles of perceptual organization and spatial distortion: The Gestalt illusions. Journal of Experimental Psychology: Human Perception \& Performance, 6, 404-412.

Curcio, C. A., Sloan, K. R., Packer, O., Hendrickson, A. E., \& KaLINA, R. E. (1987, May 1). Distribution of cones in human and mon- 
key retina: Individual variability and radial asymmetry. Science, $\mathbf{2 3 6}$, 579-582.

DUNCAN, J. (1984). Selective attention and the organization of visual information. Journal of Experimental Psychology: General, 113, 501517

Duncan, J., \& Humphreys, G. W. (1989). Visual search and stimulus similarity. Psychological Review, 96, 433-458.

Duncan, J., \& Humphreys, G. W. (1992). Beyond the search surface: Visual search and attentional engagement. Journal of Experimental Psychology: Human Perception \& Performance, 18, 578-588.

EGETh, H. E., Folk, C. L., \& Mullin, P. A. (1989). Spatial parallelism in the processing of lines, letters, and lexicality. In B. E. Shep \& S. Ballesteros (Eds.), Object perception: Structure and process (pp. 19-52). Hillsdale, NJ: Erlbaum.

Enns, J. T., \& Rensink, R. A. (1990, February 9). Influence of scenebased properties on visual search. Science, 247,721-723.

ENNS, J. T., \& RENSINK, R. A. (1991). VSearch color: Full-color visual search experiments on the Macintosh II. Behavior Research Methods, Instruments, \& Computers, 23, 265-272.

ERIKSEN, C. W. (1952). Location of objects in a visual display as a function of the number of dimensions on which the objects differ. Journal of Experimental Psychology, 44, 56-60.

ERIKSEN, C. W. (1953). Object location in a complex perceptual field. Journal of Experimental Psychology, 45, 126-132.

Eriksen, C. W., \& Rohrbaugh, J. W. (1970). Some factors determining efficiency of selective attention. American Journal of Psychology, 83, 330-343.

ESTES, W. K. (1972). Interactions of signal and background variables in visual processing. Perception \& Psychophysics, 12, 278-286.

Estes, W. K., \& WOLFORD, G. L. (1971). Effects of spaces on report from tachistoscopically presented letter strings. Psychonomic Science, 25, 77-80.

FARMER, E.W., \& TAYLOR, R. M. (1980). Visual search through color displays: Effects of target-background similarity and background uniformity. Perception \& Psychophysics, 27, 267-272.

GinsBurG, A. P. (1984). Visual form perception based on biological filtering. In L. Spillman \& B. R. Wooten (Eds.), Sensory experience, adaptation and perception (pp. 53-72). Hillsdale, NJ: Erlbaum.

GinSBURG, A. P. (1986). Spatial filtering and visual form perception. In K. R. Boff, L. Kaufman, \& J. P. Thomas (Eds.), Handbook of perception and human performance (Vol. 2, pp. 34.1-34.41). New York: Wiley.

GreEN, M. (1992). Visual search: Detection, identification, and localization. Perception, 21, 765-777.

Hıтт, W. D. (1961). An evaluation of five different abstract coding methods: Experiment IV. Human Factors, 3, 120-130.

Hubet, D. H., \& WiesEt, T. N. (1979, September). Brain mechanisms of vision. Scientific American, 241, 150-162.

Humphreys, G. W., Quinlan, P. T., \& RidDoch, M. J. (1989). Grouping processes in visual search: Effects with single- and combined-feature targets. Journal of Experimental Psychology: General, 118, 258-279.

IVRY, R. B., \& Prinzmetal, W. (1991). Effect of feature similarity on illusory conjunctions. Perception \& Psychophwsics, 49, 105-116.

Johnston, J. C., \& PAshler, H. (1990). Close binding of identity and location in visual feature perception. Journal of Experimental Psychology: Human Perception \& Performance, 16, 843-856.

Julesz, B. (1980). Spatial nonlinearities in the instantaneous perception of textures with identical power spectra. Philosophical Transactions of the Royal Society of London: Series B, 290, 83-94.

KaHNEMAN, D., \& HENIK, A. (1977). Effects of visual grouping on immediate recall and selective attention. In S. Dornic (Ed.), Attention and performance VI (pp. 307-322). Hillsdale, NJ: Erlbaum.

Kahneman, D., \& Henik, A. (1981). Perceptual organization and attention. In M. Kubovy \& J. R. Pomerantz (Eds.), Perceptual organization (pp. 181-211). Hillsdale, N.J.: Erlbaum.

Keele, S., Cohen, A., Ivry, R., LiotTi, M., \& Yee, P. (1988). Tests of a temporal theory of attentional binding. Journal of Experimental Psychology: Human Perception \& Performance, 14, 444-452.

KINCHLA, R. A. (1977). The role of structural redundancy in the perception of visual targets. Perception \& Psychophysics, 22, 19-30.

KofFKA, K. (1935). Principles of Gestalt psychology. New York: Harcourt Brace.
McLeod, P., Driver, J., \& CRISP, J. (1988). Visual search for a conjunction of movement and form is parallel. Nature, 332, 154-155.

Nakayama, K., \& Silverman, G. H. (1986). Serial and parallel processing of visual feature conjunctions. Nature, 320, 264-265.

NeISSER, U. (1967). Cognitive psychology. New York: Appleton-CenturyCrofts.

Nissen, M. J. (1985). Accessing features and objects: Is location special? In M. I. Posner \& O. S. M. Marin (Eds.), Attention and performance XI (pp. 204-218). Hillsdale, NJ: Erlbaum.

PALMER, S., \& Rock, I. (1994). Rethinking perceptual organization: The role of uniform connectedness. Psychonomic Bulletin \& Review, 1, 29-55.

Peterson, M. A., \& Gibson, B. S. (1991). Directing spatial attention within an object: Altering the functional equivalence of shape descriptions. Journal of Experimental Psychology: Human Perception \& Performance, 17, 170-182.

Peterson, M. A., \& Hochberg, J. (1983). Opposed set measurement procedure: A quantitative analysis of the role of local cues and intention in form perception. Journal of Experimental Psychology: Human Perception \& Performance, 9, 183-193.

Poisson, M. E., \& Wilkinson, F. (1992). Distractor ratio and grouping processes in visual conjunction search. Perception, 21, 21-38.

Pomerantz, J. R. (1981). Perceptual organization in information processing. In M. Kubovy \& J. R. Pomerantz (Eds.), Perceptual organization (pp. 141-180). Hillsdale, NJ: Erlbaum.

Pomerantz, J. R., \& Schwaitzberg, S. D. (1975). Grouping by proximity: Selective attention measures. Perception \& Psychophysics, 18, 355-361.

Prinzmetal, W. (1981). Principles of feature integration in visual perception. Perception \& Psychophysics, 30, 330-340.

PrinZMETAL, W., \& BANKS, W. P. (1977). Good continuation affects visual detection. Perception \& Psychophysics, 21, 389-395.

Prinzmetal, W., \& Keysar, B. (1989). Functional theory of illusory conjunctions and neon colors. Journal of Experimental Psychology: General, 118, 165-190.

Quinlan, P. T., \& HumPhREYS, G. W. (1987). Visual search for targets defined by combinations of color, shape, and size: An examination of the task constraints on feature and conjunction searches. Perception \& Psychophysics, 41, 455-472.

Rensink, R. A., \& EnNS, J. T. (1992). Vscope and Emaker [Software manual]. Vancouver, BC: Micropsych Software.

Russduk, J. P., Kroon, J. N., \& van der Wilt, G. L. (1980). Contrast sensitivity as a function of position on the retina. Vision Research, 20 , 235-241.

SAGI, D. (1990). Detection of orientation singularity in Gabor textures: Effect of signal density and spatial frequency. Vision Research, 30 , $1377-1388$

SAGI, D., \& Julesz, B. (1985a). Detection versus discrimination of visual orientation. Perception, 14, 619-628.

SaGi, D., \& Julesz, B. (1985b, June 7). "Where" and "what" in vision. Science, 228, 1217-1219.

SPERLING, G. (1960). The information available in brief presentations. Psychological Monographs, 74 (11, Whole No. 498).

Treisman, A. (1982). Perceptual grouping and attention in visual search for features and for objects. Journal of Experimental Psychology: Human Perception \& Performance, 8, 194-214.

Treisman, A. (1993). The perception of features and objects: In A. [D.] Baddeley \& L. Weiskrantz (Eds.), Attention: Selection, awareness, and control (pp. 5-35). Oxford: Oxford University Press, Clarendon Press.

Treisman, A., \& Gelade, G. (1980). A feature integration theory of attention. Cognitive Psychology, 12, 97-136.

Treisman, A., \& Gormican, S. (1988). Feature analysis in early vision: Evidence from search asymmetries. Psychological Review, 95, 15-48.

Treisman, A., \& Schmidt, N. (1982). Illusory conjunctions in the perception of objects. Cognitive Psychology, 14, 107-141.

TSAL, Y. (1983). On interpreting the effects of location preknowledge: A critique of Duncan. Perception \& Psychophysics, 34, 297-298.

VAN DER HeIJden, A. H. C. (1993). The role of position in object selection in vision. Psychological Research, 56, 44-58.

WERTHEIMER, M. (1923). Untersuchungen zur Lehre von der Gestalt. Psychologische Forschung, 4, 301-350. [Reprinted in part in W. D. Ellis 
(Ed.), A sourcebook of Gestalt psychology (pp. 71-88). New York: Humanities Press, 1950.]

WOLFE, J. M. (1992). The parallel guidance of visual attention. Current Directions in Psychological Science, 1, 124-128.

WOLFE, J. M. (1994). Guided search 2.0: A revised model of visual search. Psychonomic Bulletin \& Review, 1, 202-238.

Wolfe, J. M., Cave, K. R., \& Franzel, S. L. (1989). Guided Search: An alternative to the feature integration model for visual search. Journal of Experimental Psychology: Human Perception \& Performance, 15, 419-433.

WoLFORD, G. (1975). Perturbation model for letter identification. Psychological Review, 82, 184-199.

Wolford, G., \& SHUM, K. H. (1980). Evidence for feature perturbations. Perception \& Psychophysics, 27, 409-420.

YANTIS, S. (1992). Multielement visual tracking: Attention and perceptual organization. Cognitive Psychology, 24, 295-340.

\section{NOTE}

1. We conducted another experiment, in which eight observers localized a tilted target among 59 vertical or horizontal distractors under col- $u m n$ instructions, and eight observers did so under row instructions. The difference between the display of this experiment and that of Experiment 2 is that the regions were homogeneously coded: red, green, and blue for either the left, middle, and right regions or for the top, middle, and bottom regions. The display was presented using an overhead projector driven by a Macintosh Ilci. Only accuracy data were obtained. Each observer completed five experimental conditions of 81 trials each, color coded by rows, by horizontal regions, by columns, by vertical regions, and by monochromatic condition. The distractor orientation corresponded to the direction of the color coding (e.g., vertical distractors for vertical regions and for columns). The subjective boundary effect was present in all the conditions, except for the column instruction-vertical regions/vertical distractors, and was drastically diminished, but not eliminated, in the row instruction-horizontal regions/horizontal distractors.
(Manuscript received October 17, 1994; accepted for publication March 23, 1995.) 